\title{
Novel polyphenolic ligand of BP-Cx family drugs: cell distribution and mechanism of action
}

\author{
Fedoros E.I. ${ }^{1,2}$, Badun G.A. ${ }^{3}$, Grozdova I.D. ${ }^{3}$, Melik-Nubarov N.S. ${ }^{3}$, Perminova I.V. ${ }^{3}$, \\ Baldueva I.A. ${ }^{2}$, Danilova A.B. ${ }^{2}$, Nehaeva T.L. ${ }^{2}$, Ryakhovskiy A.A. ${ }^{4}$, Pigarev S.E. ${ }^{1,2}$, \\ Panchenko A.V. ${ }^{2}$, Anisimov V.N. ${ }^{2}$ \\ ${ }^{1}$ Nobel LTD, Saint-Petersburg, Russia, efedoros@scioco.com \\ ${ }^{2}$ Petrov National Medical Research Center of Oncology, Saint Petersburg, Russia \\ ${ }^{3}$ Lomonosov Moscow State University, Moscow, Russia \\ ${ }^{4}$ CHEMDIV LTD, Moscow District, Khimki, Russia
}

Keywords: lignin, polyphenolic ligand, GR receptor, cell distribution, dendritic cells

doi: 10.36291/HIT.2019.fedoros.089

BP-Cx-1, novel polyphenolic ligand, is a water-soluble fraction of wood lignin and is the platform for a portfolio of innovative pharmacological products such as antineoplastic agent BP-C1, radiomitigator BP-C2 and geroprotective composition BP-C3 [1]. In our previous study, a number of polyphenolic components of BP-Cx-1 (flavonoids, sapogenins, phenathrenes etc.) were identified as the major carriers of biological activity of BP-Cx drug family. In vitro and in silico target screening yielded overlapping lists of target proteins: adenosine receptors A1, A2A; dopamine receptor DRD4; glucocorticoid receptor GR; serotonin receptor 5-HT1; prostaglandin receptors PGI2, EP2; muscarinic cholinergic receptor, GABAA receptor [2]. Most of them are involved in cancer and/or inflammation signaling pathways.

In the present study, the IC50 of BP-Cx-1 was measured by radioligand method and a range of IC50 values between 22.8 and $40.3 \mu \mathrm{g} / \mathrm{ml}$ were obtained for A1, A2A, BZD, EP2 and IP (PGI2) receptors. IC50 for $5-\mathrm{HT} 1$ and for GR were $3.0 \mu \mathrm{g} / \mathrm{ml}$ and $12.6 \mu \mathrm{g} / \mathrm{ml}$, respectively, both being within the range of $\mathrm{BP}-\mathrm{Cx}-1$ concentrations detectable in in vivo models (see Panchenko et al abstract in this conference book).

Further, distribution of $[3 \mathrm{H}]$ labelled BP-Cx-1 in murine fibroblasts NIH3T3 and MCF7/R carcinoma cells was studied by autoradiography method. [3H]-BP-Cx-1 (marked by silver grains formed under tritium $\beta$-irradiation) was mainly localized along the cell membrane, in the perinuclear region and in the nucleus, suggesting ability of BP-Cx-1 to penetrate cells and bind to membrane or cytosol receptors. It is hypothesized that [3H]-BP$\mathrm{Cx}-1$ detectable in the nucleus is part of an activated GR complex, known to be involved in regulation of transcription of genes responsible for the anti-inflammatory response.

It is reported, that glucocorticoids may act at the very first step of the immune response by modulating differentiation, maturation and function of dendritic cells (DCs) [3]. In our experiment, we observed similar effect of BP-Cx-1 on DCs: downregulation of expression of the lipid-presentation molecule CD1a, co-stimulatory molecules CD80, CD86 and CD 40, decreased production of pro-inflammatory cytokines IL-4 and TNFa and increased production of anti-inflammatory cytokine IL-10. Observed production of G-CSF and GM-CSF by DCs in response to treatment with BP-Cx-1 may explain the radiomitigating effect of $\mathrm{BP}-\mathrm{C} 2$.

This work was supported by Russian Science Foundation [Grant No 16-15-00142].

References

1. Anisimov V.N. et al. // Oncotarget. 2017. 8(59):100951-100956.

2. Fedoros E.I. et al. // Oncotarget. 2018. 9(26):18578-18593.

3. Cain D.W., Cidlowski J.A. // Nature Rev. Immunology. 2017. 17(4):233-247. 